\title{
Amniotic membrane application in complex cases of penetrating keratoplasty surgery
}

\author{
Andrea Passani ${ }^{1}$, Angela Tindara Sframeli ${ }^{1}$, lacopo Franchini ${ }^{2}$, Rosario Denaro ${ }^{3}$, Mario D. Toro ${ }^{4}$, \\ Chiara Posarelli ${ }^{1}$ \\ ${ }^{1}$ Azienda Ospedaliero-Universitaria Pisana, Pisa University Hospital, Italy \\ ${ }^{2}$ Azienda Ospedaliero-Universitaria Careggi, Careggi University Hospital, Italy \\ ${ }^{3}$ U. O. Oculistica USL1 Massa e Carrara, Italy \\ ${ }^{4}$ Eye Clinic, University of Catania, Catania, Italy
}

\begin{abstract}
INTRODUCTION. The aim of the study is to investigate the ability of an amniotic membrane implant combined with penetrating keratoplasty to reduce early and mid-term complications in complex cases such as penetrating burns, infective ulcers, keratitis, or corneal graft failure.

MATERIALS AND METHODS. Fifty patients: 12 with keratitis, 24 with infective ulcers, 10 with penetrating trauma, and four with a history of corneal graft failure, were divided into two groups. The first group of 25 patients (Group A) underwent penetrating keratoplasty alone, while the second group of 25 patients (Group B) received penetrating keratoplasty associated with an amniotic membrane implant. Amniotic membrane implantation was performed in a 'patch modality', and the membrane was sewn to the graft with the epithelium/basement membrane side facing inwards. All patients were evaluated, respectively, 3, 15, 30, 90, and 180 days after surgery. At each visit a slit-lamp examination was performed together with corneal thickness and endothelial cell count assessment. All the data were subjected to statistical analysis with Student's t-test.

RESULTS. At the slit-lamp examination in Group A 48\% of patients showed Descemet folds at one and three months, respectively, while $80 \%$ of patients of Group B did not show any Descemet folds. In Group A we registered two cases of early graft failure and two cases of shallow anterior chamber, while none of these complications appeared in Group B. In Group A the average corneal thickness at 15, 30, 90, and 180 days post-operatively was, respectively, $695 \pm 43 \mu \mathrm{m}, 658 \pm 31 \mu \mathrm{m}, 588 \pm 12 \mu \mathrm{m}$, and $518 \pm 20 \mu \mathrm{m}$, while in Group B it was found to be, respectively, $667 \pm 12 \mu \mathrm{m}, 632 \pm 17 \mu \mathrm{m}, 562 \pm 16 \mu \mathrm{m}$, and $516 \pm 10 \mu \mathrm{m}$. Differences in corneal thickness between Group $A$ and Group B were found to be statistically significant $(\mathrm{p}=0.05)$. Endothelial cell count was in Group A $2582 \mathrm{c} / \mathrm{mm}^{2}$ at 15 days, $2500 \mathrm{c} / \mathrm{mm}^{2}$ at one month, $2335 \mathrm{c} / \mathrm{mm}^{2}$ at three months, and $2111 \mathrm{c} / \mathrm{mm}^{2}$ at six months, while the average count for Group B patients was $2607 \mathrm{c} / \mathrm{mm}^{2}, 2503 \mathrm{c} / \mathrm{mm}^{2}, 2299 \mathrm{c} / \mathrm{mm}^{2}$, and $2086 \mathrm{c} / \mathrm{mm}^{2}$, respectively. Differences in endothelial cell count between the two groups did not show any statistical significance ( $p>0.05)$.

CONCLUSIONS. Amniotic membrane implantation associated with penetrating keratoplasty reduces early and mid-term complications of corneal grafts in patients with high risk of failure. This positive effect may be due to the anti-inflammatory, neurotrophic, and anti-angiogenetic properties of the amniotic membrane. Longer observation and larger case series can be useful in evaluation of the functional outcome of grafts in these patients.
\end{abstract}

KEY WORDS: amniotic membrane, complex cases, graft survival, inflammatory response, penetrating keratoplasty surgery

Ophthalmol J 2017; Vol. 2, No. 4, 101-104 


\section{INTRODUCTION}

The regular post-operative course of penetrating keratoplasty surgery (PK) may be affected by shortand medium-term complications such as delay in re-epithelialisation, persistence of corneal oedema, shallow anterior chamber, inflammation of corneal epithelium, and, above all, graft rejection. These complications are more frequent in patients in whom PK is meant to treat "complex" clinical and anatomical situations such as corneal opacity from perforating injury, corneal neovascularisation due to inflammatory or infectious processes, and rejection of previous PK treatments. In these situations, graft survival is endangered by an excessive inflammatory response as long as functional deficiencies that may lead to graft rejection. To reduce inflammatory response and to minimise epithelial defects connected to stem cell deficiency, an amniotic membrane implant may help graft survival and reduce postoperative complications. Amniotic membrane (AM) has anti-inflammatory, neurotrophic, and anti-angiogenic properties, and it is used in several ophthalmologic situations [1-4]. The objective of this study is to investigate if the application of amniotic membrane associated with penetrating keratoplasty surgery could help managing patients with "complex" corneal pathologies.

\section{MATERIALS AND METHODS}

Fifty patients (30 men and 20 women) participated in our study, with an average age of 62.3 years. All patients presented severe corneal opacities due to (Fig. 1):

- Prior keratitis (12 cases)

- Prior corneal ulcer (24 cases)

- Prior penetrating trauma of the anterior segment (10 cases)

- History of graft failure (four cases)

The patients were randomised in a 1:1 ratio into two groups: the subjects in Group A (25 patients: five prior keratitis, 12 prior corneal ulcers, seven prior penetrating trauma, and one case of previous graft failure) underwent standard PK surgery, while subjects in Group B (25 patients: seven prior keratitis, 12 prior corneal ulcers, three prior penetrating trauma, and three cases of previous graft failure) underwent PK surgery associated with the application of a single-layer amniotic membrane patch. Corneas used for surgery presented an average endothelial cell density of 2720 cells $/ \mathrm{mm}^{2}$ (range between 2400 and 2950 cells $/ \mathrm{mm}^{2}$ ) while a single layer of AM was applied with the "patch method" (epithelium membrane facing the graft and stromal side facing outwards). The AM was sutured to the sclera using 10-0 nylon sutures and protected with a contact lens placed at the end of the surgery. The contact lens and amniotic membrane patch were removed 15 days after PK surgery. All patients were re-examined $3,15,30,90$, and 180 days after surgery with a slit-lamp examination. At 15, 90 , and 180 days after surgery both pachymetry and endothelium cell density (EM-3000, Tomey, Japan) were registered. The parameters evaluated at each visit were: corneal transparency and oedema of the graft; Seidel test and reduction of anterior chamber depth; inflammation of the anterior segment; epithelial and/or endothelial distress signs and early rejection signs. The statistical analysis of collected data was performed with Student's t-test for paired data.

\section{RESULTS}

Three, 15, and 30 days after surgery 10 patients $(40 \%)$ of Group A presented signs of superficial punctate keratopathy, 12 patients presented Descemet folds (48\%), and two subjects showed a shallow anterior chamber (Seidel positive). Three months after surgery Descemet folds persisted in five of the 12 initial cases, and two cases of early graft rejection were identified. In Group B Descemet folds were detected in only five patients (at 30 days post-surgery), while no cases of shallow anterior chamber or early rejection were reported. In Group A the average corneal thickness at 15, 30,90 , and 180 days post-operatively was, respectively, $695 \pm 43 \mu \mathrm{m}, 658 \pm 31 \mu \mathrm{m}, 588 \pm 12 \mu \mathrm{m}$, and $518 \pm 20 \mu \mathrm{m}$, while in Group B it was found to be, respectively, $667 \pm 12 \mu \mathrm{m}, 632 \pm 17 \mu \mathrm{m}$, $562 \pm 16 \mu \mathrm{m}$, and $516 \pm 10 \mu \mathrm{m}$ (Fig. 2). Differences in corneal thickness between Group $A$ and Group B were found to be statistically significant $(\mathrm{p}=0.05)$. Endothelial cell count in Group A was $2582 \mathrm{c} / \mathrm{mm}^{2}$ at 15 days, $2500 \mathrm{c} / \mathrm{mm}^{2}$ at one month, $2335 \mathrm{c} / \mathrm{mm}^{2}$ at three months, and $2111 \mathrm{c} / \mathrm{mm}^{2}$ at six months, while the average count for Group B patients was $2607 \mathrm{c} / \mathrm{mm}^{2}, 2503 \mathrm{c} / \mathrm{mm}^{2}, 2,299 \mathrm{c} / \mathrm{mm}^{2}$, and $2086 \mathrm{c} / \mathrm{mm}^{2}$, respectively. The percentage reduction in the number of endothelial cells in the first six months post-surgery was $18.4 \%$ in Group A and $19.9 \%$ in Group B. Differences in endothelial cell count between the two groups did not show any statistical significance $(\mathrm{p}>0.05)$. 


\section{DISCUSSION}

Regular post-operative course of penetrating keratoplasty surgery may be affected by short- and medium-term complications. In our experience these complications occur more frequently in those patients where an extensive damage to the ocular surface results in limbal stem cell deficiency [5, 6] (for example, in the case of recurrent corneal ulcers, prolonged inflammation and infection of the cornea, traumas, etc.). In these cases attachment issues with the transplanted graft are frequently observed and may predispose the patient to inflammatory processes and early rejection due to the aforementioned limbal stem cell deficiency [7-10]. Attachment issues of the graft (such as graft early rejection) are revealed by the presence of areas of epithelial distress, Descemet folds, persistence of significant de-epithelialisation, stromal oedema, and reduced viability of vascular endothelial cells [11-14].

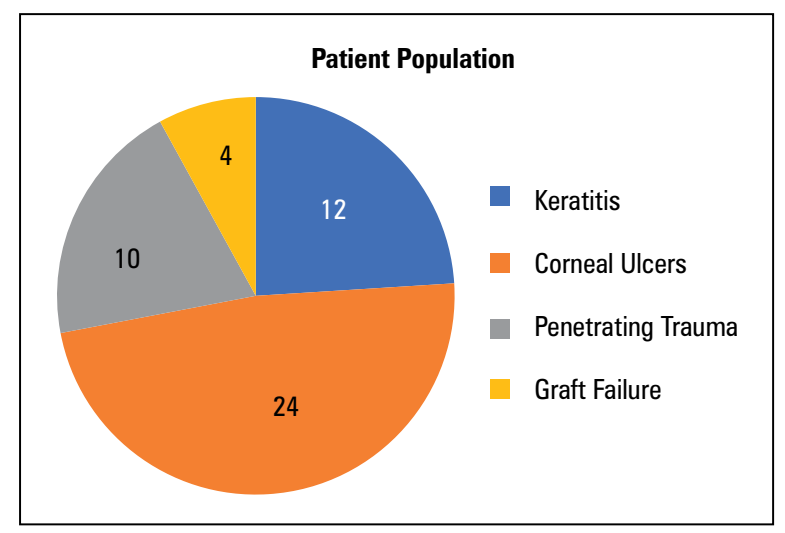

FIGURE 1. Causes for penetrating keratoplasty in our case series (50 subjects)
In all these situations the proper attachment of the graft to the recipient's eye is endangered and the risk of graft rejection is greatly increased. Because these cases are relatively unresponsive to medical therapy, we hypothesised that AM application in combination with PK surgery could improve post-operative performance when compared with traditional PK surgery outcomes. AM application after PK surgery has been previously described, but no comparative studies have been published $[15,16]$. AM application may in fact improve post-operative outcomes thanks to the restoration of an intact basement membrane on its epithelial side. This may promote proliferation, migration, and differentiation of epithelial cells while maintaining their clonogenicity [17-19]. On the other hand, the stromal surface may inhibit the proliferation of fibroblasts and inflammatory cells through the suppression of the TGF $\beta$ signal and the release of protease inhibitors and growth factors [20-22]. This stromal ability may therefore prevent inflammation and fibrosis. Using the patch method for AM application (stromal side facing outwards) the corneal epithelium can achieve an intact basement membrane, which promotes growth beneath the AM graft and guarantees faster re-epithelialisation of the flap. Improving the re-epithelialisation of the flap is a primary objective of post-operative management because it reduces infectious risk and prevents the fibrosis due to the neovascularisation connected to repeated re-epithelialisation attempts. Moreover, Group $\mathrm{B}$ patients demonstrate that AM application acts as an occlusive bandage and ensures normal anterior chamber depth and intraocular pressure (no cases of shallow anterior chamber). While the healing prop-

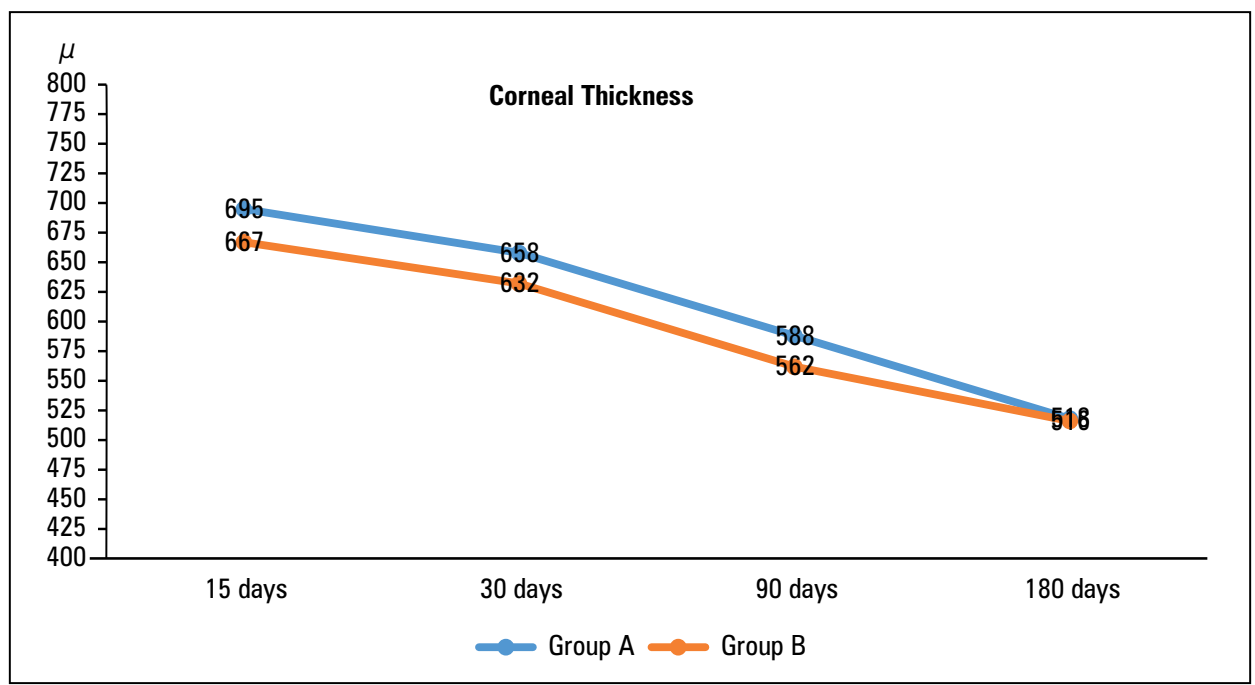

FIGURE 2. Postoperative mean corneal thickness $(\mu)$ in Group A vs. Group B 
erties of AM's epithelial component act in the first post-operative phase the stromal cells regulate progress in the short-medium term through the inhibition of inflammation and fibrosis. These properties explain the faster resolution of oedema and Descemet folds observed in Group B patients. These hypotheses are demonstrated by the fact that, in Group B patients, not only did the Descemet folds resolve faster but also the thickness of the flap (indicative of the presence of oedema) reduced more quickly. At the time of AM removal (on the $15^{\text {th }}$ day) there was in fact a major difference in the thickness of the flap between the two sample groups, which was maintained in the subsequent examinations. These differences in corneal thickness were statistically significant at the performed Student's t-test for paired data $(\mathrm{p}=0.05)$. Regarding corneal thickness, the patients who underwent AM application showed much more homogeneous data than the patients treated with PK alone. This effect is attributable to AM anti-inflammatory activity that was able to contain the flap's inflammatory oedema. However, the percentage reduction of corneal thickness at 30,90, and 180 days after surgery was similar in the two groups and was not statistical significant $(\mathrm{p}>0.05)$. These outcomes indicate that AM's anti-oedema effect is most notable during the initial membrane's stabilisation phase and it decreases in later months. Nevertheless, early inflammation resolution decreases the risk of neovascularisation and early rejection and is therefore a very important property of the AM, which can help us to manage complex PK surgeries. Regarding endothelium cell count, our research did not reveal any impact from AM. Assessment of the endothelial count showed, in fact, a progressive reduction in the cell population of the transplanted flap, which is comparable between the two groups in the early and late post-operative phase.

\section{CONCLUSIONS}

The results of our research suggest the possibility of using the restorative, anti-inflammatory, neurotrophic and anti-angiogenic properties of AM to boost the vitality of the transplanted flap and the functional recovery process of the cornea. AM application may also reduce the risk of early rejection, re-epithelialisation failure, neovascularisation, anterior chamber depth reduction, and inflammatory processes of the transplanted flap.

\section{REFERENCES}

1. Jirsova $K$, Jones GLA. Amniotic membrane in ophthalmology: properties, preparation, storage and indications for grafting-a review. Cell
Tissue Bank. 2017; 18(2): 193-204, doi: 10.1007/s10561-017-9618-5, indexed in Pubmed: 28255771.

2. Rahman I, Said DG, Maharajan VS, et al. Amniotic membrane in ophthalmology: indications and limitations. Eye (Lond). 2009; 23(10): 1954-1961, doi: 10.1038/eye.2008.410, indexed in Pubmed: 19169225.

3. Gomes JAP, Romano A, Santos MS, et al. Amniotic membrane use in ophthalmology. Curr Opin Ophthalmol. 2005; 16(4): 233-240, doi: 10.1097/01.icu.0000172827.31985.3a, indexed in Pubmed: 16000896.

4. Dua H, Gomes J, King A, et al. The amniotic membrane in ophthalmology. Surv Ophthalmol. 2004; 49(1): 51-77, doi: 10.1016/j.survophthal.2003.10.004, indexed in Pubmed: 14711440.

5. Duchesne B, Mans B, Lavalleye B, et al. [Use of the cryopreserved human amniotic membrane for reconstruction of the ocular surface]. Bull Soc Belge Ophtalmol. 1998; 268: 73-77, indexed in Pubmed: 9810086.

6. Tseng S. Amniotic Membrane Transplantation With or Without Limbal Allografts for Corneal Surface Reconstruction in Patients With Limbal Stem Cell Deficiency. Archives of Ophthalmology. 1998; 116(4): 431, doi: 10.1001/archopht.116.4.431.

7. Amniotic membrane transplantation for severe neurotrophic corneal ulcers. Chen H-J, Pires RTF, Tseng SCG*(1). Br J Ophthalmol 2000;84:826833. Am J Ophthalmol. 2001; 131(1): 155-156, doi: 10.1016/s00029394(00)00918-1, indexed in Pubmed: 11341884.

8. Chen HJ, Pires RT, Tseng SC. Amniotic membrane transplantation for severe neurotrophic corneal ulcers. Br J Ophthalmol. 2000; 84(8): 826-833, doi: 10.1136/bjo.84.8.826, indexed in Pubmed: 10906085.

9. Shimazaki J, Yang HY, Tsubota K. Amniotic membrane transplantation for ocular surface reconstruction in patients with chemical and thermal burns. Ophthalmology. 1997; 104(12): 2068-2076, doi: 10.1016/s01616420(97)30057-8, indexed in Pubmed: 9400767.

10. Prabhasawat $P$, Tesavibul N, Komolsuradej W. Single and multilayer amniotic membrane transplantation for persistent corneal epithelial defect with and without stromal thinning and perforation. Br J Ophthalmol. 2001; 85(12): 1455-1463, doi: 10.1136/bjo.85.12.1455, indexed in Pubmed: 11734521.

11. Feiz V, Mannis MJ, Kandavel G, et al. Surface keratopathy after penetrating keratoplasty. Trans Am Ophthalmol Soc. 2001; 99: 159-168.

12. Wagoner MD, Ba-Abbad R, Al-Mohaimeed M, et al. King Khaled Eye Specialist Hospital Corneal Transplant Study Group. Postoperative complications after primary adult optical penetrating keratoplasty: prevalence and impact on graft survival. Cornea. 2009; 28(4): 385-394, doi: 10.1097/ IC0.0b013e31818d3aef, indexed in Pubmed: 19411956.

13. Stechschulte SU, Azar DT. Complications after penetrating keratoplasty. Int Ophthalmol Clin. 2000; 40(1): 27-43, doi: 10.1097/00004397200001000-00005, indexed in Pubmed: 10713912.

14. Armitage WJ, Dick AD, Bourne WM. Predicting endothelial cell loss and long-term corneal graft survival. Invest Ophthalmol Vis Sci. 2003; 44(8): 3326-3331, doi: 10.1167/iovs.02-1255, indexed in Pubmed: 12882777.

15. Koizumi N, Fullwood NJ, Bairaktaris G, et al. Cultivation of corneal epithelial cells on intact and denuded human amniotic membrane. Invest Ophthalmol Vis Sci. 2000; 41(9): 2506-2513, indexed in Pubmed: 10937561.

16. Khodadoust AA, Silverstein AM, Kenyon DR, et al. Adhesion of regenerating corneal epithelium. The role of basement membrane. Am J Ophthalmol. 1968; 65(3): 339-348, doi: 10.1016/0002-9394(68)93082-1, indexed in Pubmed: 5640539.

17. Kurpakus MA, Stock EL, Jones JC. The role of the basement membrane in differential expression of keratin proteins in epithelial cells. Dev Biol. 1992; 150(2): 243-255, doi: 10.1016/0012-1606(92)90239-d, indexed in Pubmed: 1372569.

18. LiDQ, Lee SB, Tseng SC. Differential expression and regulation of TGF-beta1, TGF-beta2, TGF-beta3, TGF-betaRI, TGF-betaRIl and TGF-betaRIII in cultured human corneal, limbal, and conjunctival fibroblasts. Curr Eye Res. 1999; 19(2): 154-161, indexed in Pubmed: 10420185.

19. Li DQ, Tseng SC. Differential regulation of cytokine and receptor transcript expression in human corneal and limbal fibroblasts by epidermal growth factor, transforming growth factor-alpha, platelet-derived growth factor B, and interleukin-1 beta. Invest Ophthalmol Vis Sci. 1996; 37(10): 2068-2080, indexed in Pubmed: 8814146.

20. Li DQ, Tseng SC. Three patterns of cytokine expression potentially involved in epithelial-fibroblast interactions of human ocular surface. J Cell Physiol. 1995; 163(1): 61-79, doi: 10.1002/jcp.1041630108, indexed in Pubmed: 7896901. 